\title{
STEAM DRIVEN ABSORPTION HEAT PUMP AND FLUE GAS CONDENSER APPLIED FOR HEAT RECOVERY IN DISTRICT HEATING NETWORK
}

\author{
Dmitrijs Rusovs, Varis Zentins \\ Riga Technical University, Latvia \\ dmitrijs.rusovs@rtu.lv, zentins.varis@gmail.com
}

\begin{abstract}
Application of a flue gas condenser becomes a common solution for improvement of the boiler energy balance. As a result, the efficiency of the boiler becomes above $100 \%$ in reference to the fuel lower heating value (without flue gas steam condensation). However, efficient condensation of flue gas humidity is possible at low temperature of energy recovery. The dew point of the boiler flue gas is about $50-60{ }^{\circ} \mathrm{C}$ representing the threshold of flue gas efficient recovery and depends on the temperature of return water from the district heating network. Profound cooling of flue gas (below $40-45^{\circ} \mathrm{C}$ ) is not possible by direct heat exchange between the flue gas and network return water. The presented paper considers retrofit of an existing flue gas condenser heat exchanger system by implementation of an absorption heat pump (AHP). Deep cooling of flue gas will reduce the fuel consumption and ensure mitigation of carbon emission. The lithium-bromide absorption chiller unit (ACU) with rated capacity $2.1 \mathrm{MW}$ is integrated with the flue gas condenser of a natural gas-fired heat only boiler (HOB) with the purpose to increase energy recovery from flue gas. The single effect steam driven ACU was converted in AHP by the following connection: part of the return district heating flow (about $350 \mathrm{~m}^{3} \cdot \mathrm{h}^{-1}$ ) at temperature of $40^{\circ} \mathrm{C}$ degrees was warmed up in the condenser and absorber of AHP up to $52^{\circ} \mathrm{C}$ degrees. Superheated water steam at pressure about 0.8 bar (g) with total input power of 1,5 MW was used as the energy source for the generator of AHP. Water circulated in the low temperature section of the flue gas condenser was cooled down from $28^{\circ} \mathrm{C}$ degrees to $16^{\circ} \mathrm{C}$ in the evaporator of AHP. This part of the flue gas condenser extracts from the flue gas latent energy for recovery of $2.5 \mathrm{MW}$ in the condenser and absorber of AHP. The paper provides analysis of the AHP coefficient of performance (COP) for wide range of HOB power from 40 to $80 \mathrm{MW}$ and for different temperatures of the network return water.
\end{abstract}

Keywords: heating, district, condensate, efficiency, recovery.

\section{Introduction}

The climate change threat requests immediate actions for energy efficiency improvement. Energy recovery from boiler flue gas is well known for a long time. However, deep flue gas cooling for energy recovery still requests additional research efforts. The presented paper considers the performance of an industrial scale natural gas fired boiler with enhanced heat recovery by application of an absorption heat pump.

Fuel moisture and hydrogen as fuel component cause significant humidity concentration in flue gas. Condensation of the humidity from exhaust gas will increase the efficiency of combustion and decrease the emission rate per energy unit. For an example, combustion of methane formed in the reaction product at least 2.25 kilograms of water steam per kilogram of methane. Condensation of this steam amount will return in energy balance from 4 to $5 \mathrm{MJ}$ per kilogram of fuel. Therefore, condensation of moisture from exhaust gas becomes an indispensable part for modern boiler systems. However, efficient heat recovery from flue gas condensation becomes possible only below the dew point temperature of flue gas. For heating load the value of return temperature determines the condensation rate and efficiency of heat recovery from condensation. The diagram in Fig. 1 presents the condensation rate and heat recovery depending on the flue gas temperature after combustion of natural gas composed mostly of hydrocarbon according to data [1].

Return temperature from the district heating network depends on the ambient temperature and design of the system; it cannot be lower than $35-45^{\circ} \mathrm{C}$. From Fig. 1 diagram, it is possible to see that at $45^{\circ} \mathrm{C}$ condensing temperature only half of all moisture will be condensed. Due to that, significant effort was devoted to increase heat recovery by profound flue gas cooling. Application of the absorption heat pump (AHP) is a very efficient way to enhance latent heat extraction from the flue gas moisture at the temperature level substantially lower than for the return flow from the network.

Actually, AHP operates in similar way as the absorption chiller unit (ACU): it takes driving energy from high temperature carrier (steam, hot water or flue gas, etc.) for use in the generator and extracts latent heat from flue gas at low temperature in the evaporator of AHP. Then the sum of these energies will be used for warming up of the return water flow from the network in the absorber and 
condenser of AHP. In case of just cooling duty for the chiller ACU, this total energy will be dissipated through the cooling tower without recovery.

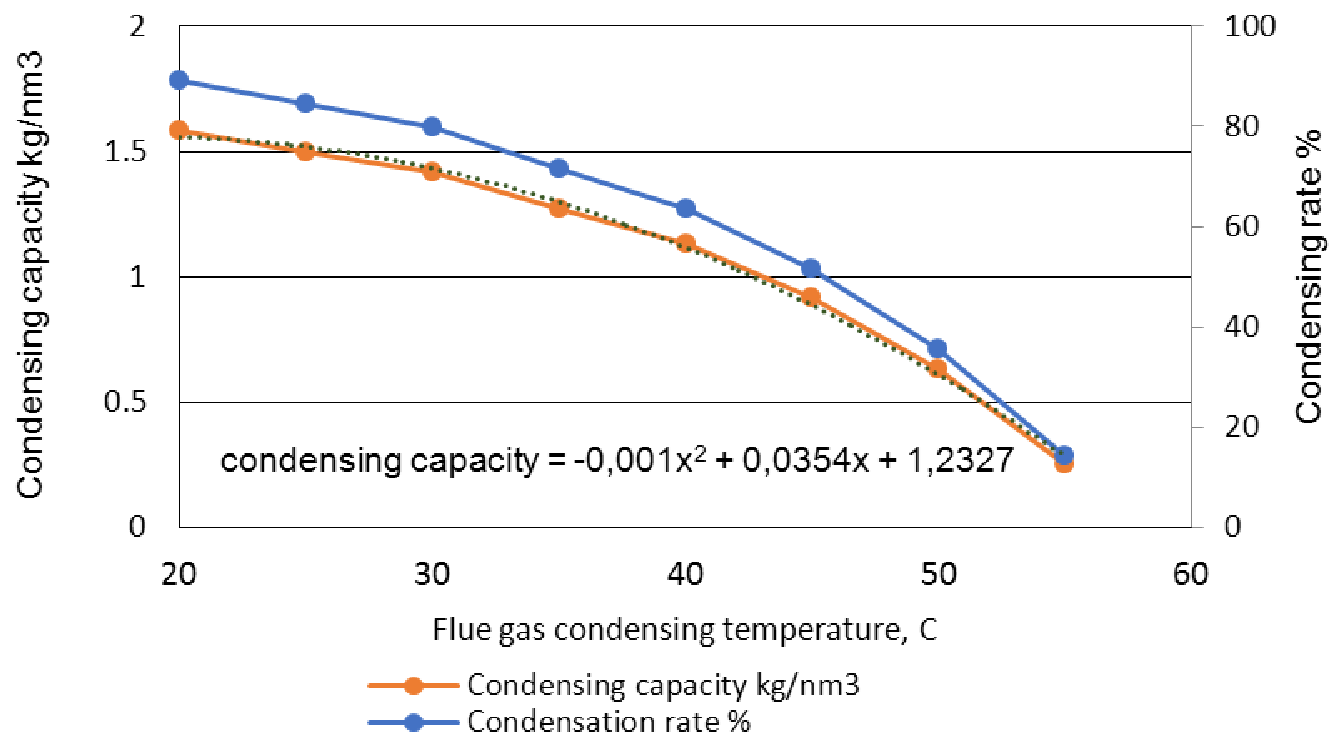

Fig. 1. Latent heat recovery from flue gas after combustion of natural gas [1]

If the temperature of flue gas can be reduced to $25-35^{\circ} \mathrm{C}$, the thermal efficiency of the gas-fired HOB could be improved up to $16 \%$ [2].

Practical use of AHP for a biomass boiler with rated power $100 \mathrm{~kW}$ for two years was discussed in [3]. An open absorption heat pump (OAHP) with the boiler for wet biofuel ensures reduction of solid particle emission by 33-44\% and increase in the heat output by $40 \%$. The absorption system provides further reduction of temperature and water in flue gas. The open absorption system is composed from three main parts: the absorber, where flue gas will be cooled down, the generator, where water will be evaporated from diluted solution, and the condenser, where evaporated steam condensates at higher pressure. Latent heat of condensation ensures energy recovery. The experimental results for fuel with the moisture content $50.9 \%$ show that an open absorption system will recover up to $44 \%$ of energy from flue gas in comparison with $23 \%$ recovery in case of water scrubber application. The open absorption system is superior to a water scrubber also because of dew point limitation, a major obstacle for latent heat recovery causes less reduction in case of the absorption system.

When OAHP is applied to the district heating system, the heat supplied to system $Q_{\text {sup }}$ consist from $Q_{d r}$ driving energy (from hot flue gas or steam) and $Q_{r e c}$ sensible and latent heat recovered from flue gas. Coefficient of Performance - COP is used to evaluate the OAHP efficiency [4]. Based on the real value of driving heat, $\mathrm{COP}$ had following definition

$$
\mathrm{COP}=\frac{Q_{\text {sup }}}{Q_{\text {sup }}-Q_{\text {rec }}} .
$$

The flue gas waste heat recovery efficiency is defined as real heat recovery $Q_{\text {rec }}$ divided by the maximum possible heat recovery, if flue gas is cooled and dehumidified to the environment level.

The OAHP driven by high-temperature flue gas used for a coal-fired boiler provides efficient heat recovery even at high return temperature. For the driving flue gas temperature of $1600{ }^{\circ} \mathrm{C}$ and the return temperature from the network of $55^{\circ} \mathrm{C}$, the OAHP achieves exit dew point of $26.8^{\circ} \mathrm{C}$. The $\mathrm{COP}$ value for these parameters was 1.762 [5].

The target of our research is to develop empirical relation of the heat recovery rate for different operation condition of HOB with AHP and FGC. The energy recovery follows the HOB power output. In real heating operation, the power demand ramp rate requests careful consideration of the network thermal inertia impact [6] and planning of energy storage charging according to [7] presented market 
demand. Since that, combination of empirical relation for recovery with thermal inertia data under the planning condition will open a way to the heating network performance simulation and further improvement.

\section{Materials and methods}

The power consumption of the District Heating Network (DHN), temperatures of direct and return flow $T 1$ and $T 2$ depends from ambient conditions and other factors. Considered natural gas-fired HOB provides the power output from 40 to $80 \mathrm{MW}$ with the return temperature $T 2$ from $39^{\circ} \mathrm{C}$ to $44^{\circ} \mathrm{C}$. Firstly, hot flue gas after $\mathrm{HOB}$ at $120^{\circ} \mathrm{C}$ enters in the front part of $\mathrm{FGC}$, where the return water flow with the inlet temperature of $T 2$ can ensure cooling of flue gas to $50^{\circ} \mathrm{C}$.

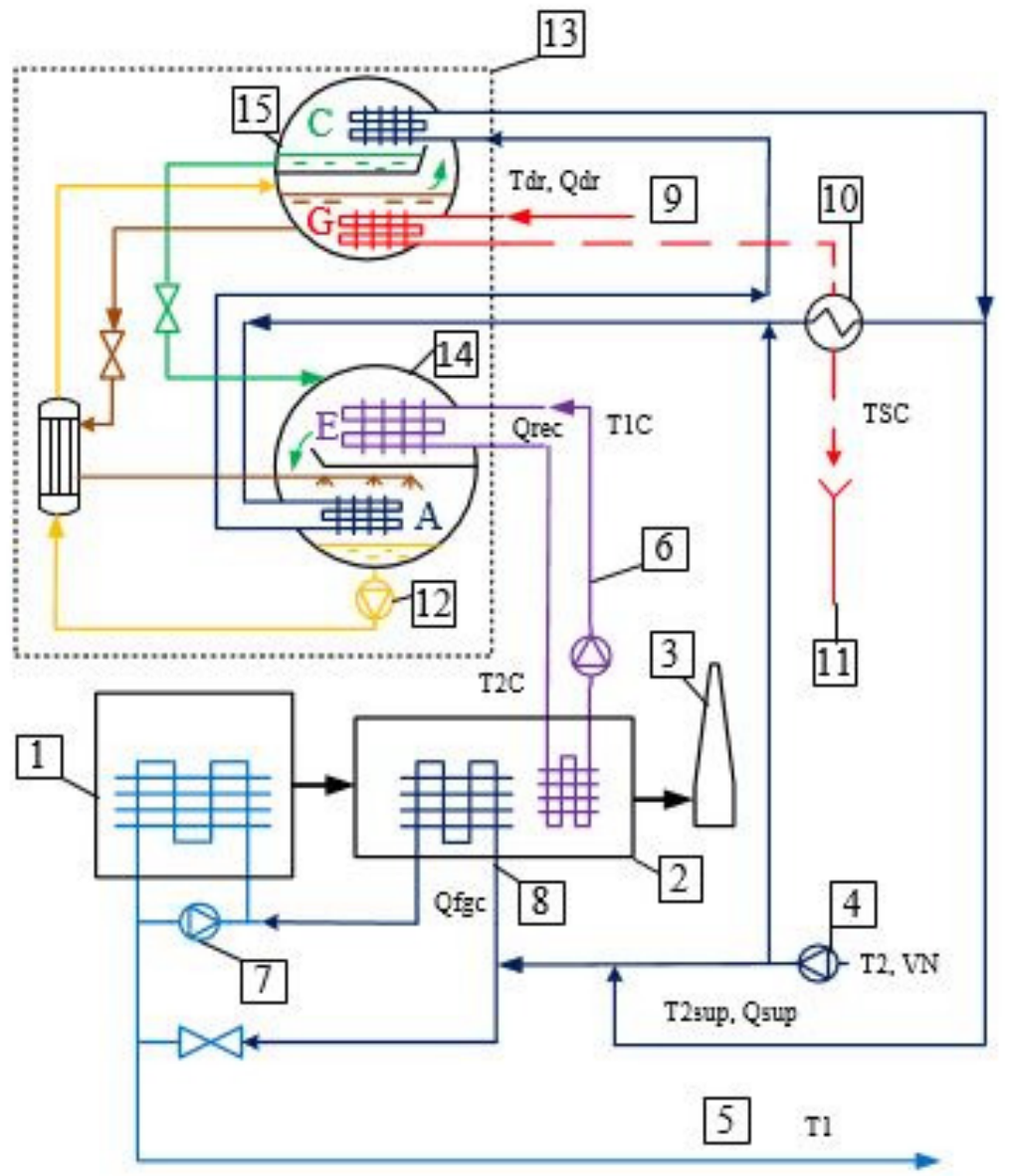

Fig. 2. Absorption heat pump and flue gas condenser operation for energy recovery : 1 - heat only boiler (HOB); 2 - flue gas condenser (FGC); 3 - chimney; 4 - network circulation pump, return water from district heating network (DHN); 5 - direct water to DHN; 6 - flue gas energy condensing loop for AHP evaporator (E); 7 - HOB recirculation pump; 8 - flue gas energy loop; 9 - water steam supply for AHP; 10 - water steam condenser cooler; 11 - water steam condensate drain; 12 - weak solution circulation pump; 13 - absorption heat pump (AHP); 14- evaporator (E) and absorber (A);

$$
15 \text { - condenser }(\mathrm{C}) \text { and generator }(\mathrm{G})
$$

The purpose of the flue gas condenser (FGC) combination with AHP was to decrease the flue gas temperature lower than $T 2$ level. The single effect lithium-bromide steam driven absorption chiller unit (ACU) was converted in AHP. Initially, ACU had rated cooling power of $2.1 \mathrm{MW}$ for chilled water flow of $70 \mathrm{~m}^{3} \cdot \mathrm{h}^{-1}$ cooleddown from $55^{\circ} \mathrm{C}$ to $29^{\circ} \mathrm{C}$. Rated water steam power for ACU generator was 2.7 MW. Therefore, ACU had rated cooling operation $\mathrm{COP}=0.78$.

Water circulation of $110 \mathrm{~m}^{3} \cdot \mathrm{h}^{-1}$ in a closed loop formed from the last section of FGC and the AHP evaporator ensures temperature in FGC between $T 1 C=17^{\circ} \mathrm{C}$ and $T 2 C=25^{\circ} \mathrm{C}$. The $Q_{\text {rec }}-$ amount of flue gas sensitive and latent energy extracted in FGC was released in AHP for water evaporation at 
low temperature. Then evaporated water becomes absorbed by strong $\mathrm{Li}-\mathrm{Br}$ solution with energy release. Received weak solution had enough temperature and was cooled down by the return water flow with temperature of $T 2$. The return water flow in AHP was limited by rated capacity and was about $350 \mathrm{~m}^{3} \cdot \mathrm{h}^{-1}$. This flow after warming up in the absorber enters the condenser of AHP, where $Q_{d r}$ - steam driving generator energy should be balanced by return DHN flow. The return water flow obtains energy in the absorber $-Q_{\text {rec }}$ and in the condenser $Q_{d r}$. Then the return water flow delivers total energy $Q_{s u p}=Q_{d r}+Q_{\text {rec }}$ at temperature $T 2_{\text {sup }}$ to the main DHN return water flow.

The heat extraction from flue gas at $T 1 C$ and $T 2 C$, which is lower than $T 2$, allows to increase the condensation rate and total heat recovery. Application of steam for driving of AHP is not very efficient from the energy saving position. But it allows to use standard ACU and additional energy recovery from the steam condensate provided in the condenser cooler 10 in Fig. 2.

\section{Results and discussion}

The data presented in Fig.3, Fig.4 and Fig.5 were obtained by temperature and flowrate measurements in given points according to Fig.2 every hour during the investigated operation period with industrial level of accuracy. The quantity spread of power and COP (calculated by (1)) in the considered diagrams occurs due to the wide range of operating parameters, like HOB power and return temperature $T 2$.

Sizing of AHP power $Q_{s u p}$ for rated HOB output can be done by evaluation of the AHP performance.

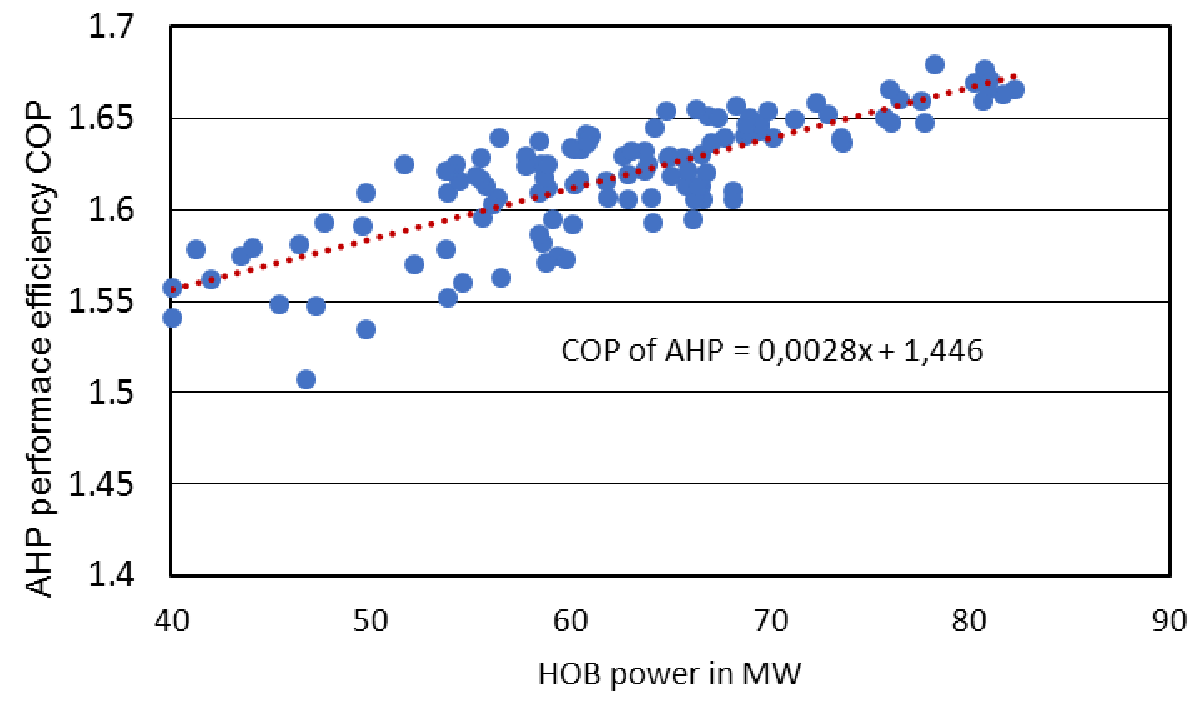

Fig. 3. Absorption heat pump COP (1) for different HOB power output

The significant fluctuation of AHP COP for changing the HOB power can be explained by different values of the return temperature $T 2$ and the amount of driving water stem energy $Q_{D R}$. It is important to take in account the pressure in the cylinders of AHP. Trend line in Fig .3 shows that COP increases, when the flue gas amount is growing together with the water steam amount after natural gas combustion. The AHP driving water steam power $Q_{D R}$ ensures low temperature for waste heat recovery during profound flue gas cooling. However, Fig. 4 demonstrates increase of COP for AHP, when the evaporator temperature is growing. The behavior of AHP can be described by the following way: COP increases in general with increasing of the evaporating temperature.

The temperature in AHP evaporator depends on cooling of the associated absorber or on the return water temperature $T 2$. The value of the return temperature $T 2$ delivers information to HOB about the heat demand in DHN. When the heat consumption in DHN is growing, then T2 is decreasing. Control system of HOB increases the fuel supply and after definite time the value of $T 2$ recovers and follows the designed temperature chart for different ambient temperature. Thermal inertia of $\mathrm{HOB}$ and DHN make $T 2$ relation with $\mathrm{HOB}$ power output quite indefinite. For example, $T 2=42{ }^{\circ} \mathrm{C}$ can be for $\mathrm{HOB}$ power in the range from 45 to $80 \mathrm{MW}$. 


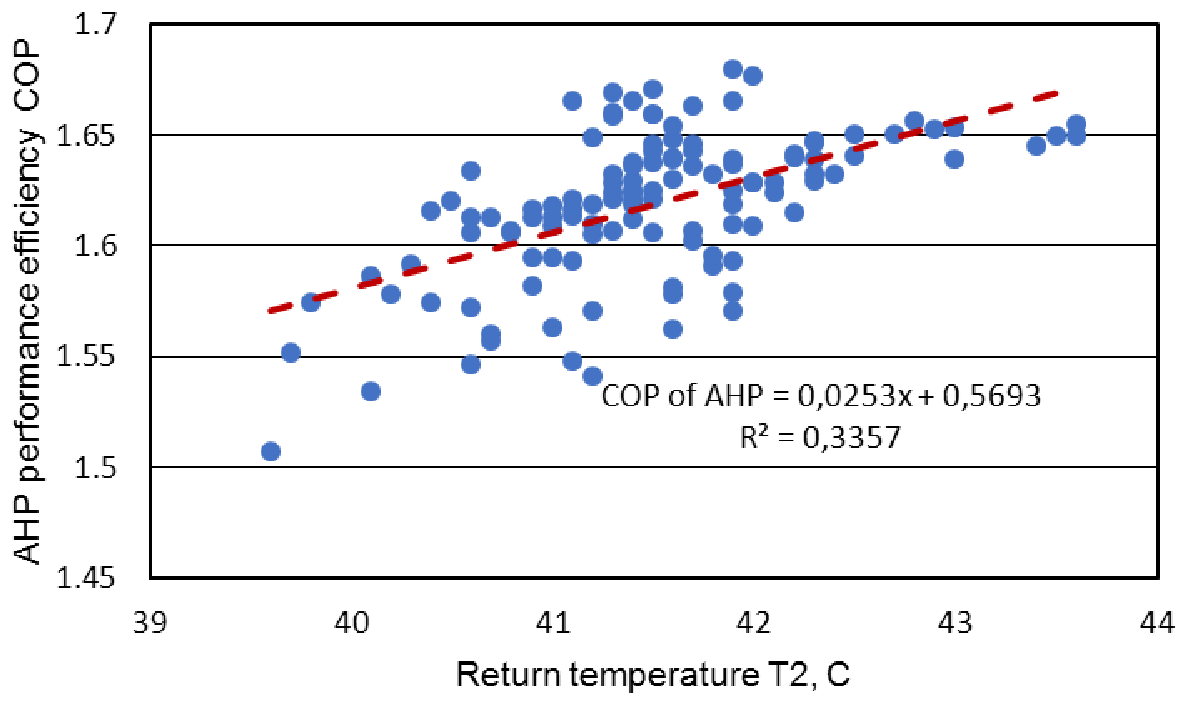

Fig. 4. Absorption heat pump COP (1) for different return temperature

The sensitive and latent heat energy of flue gas should be proportional to the amount of fuel. Hence, recovery of waste heat should grow together with the HOB power output. Fig. 5 demonstrates increased energy recovery in FGC in total (top line) and separate power of the first and last section (cooled down by AHP) of FGC.

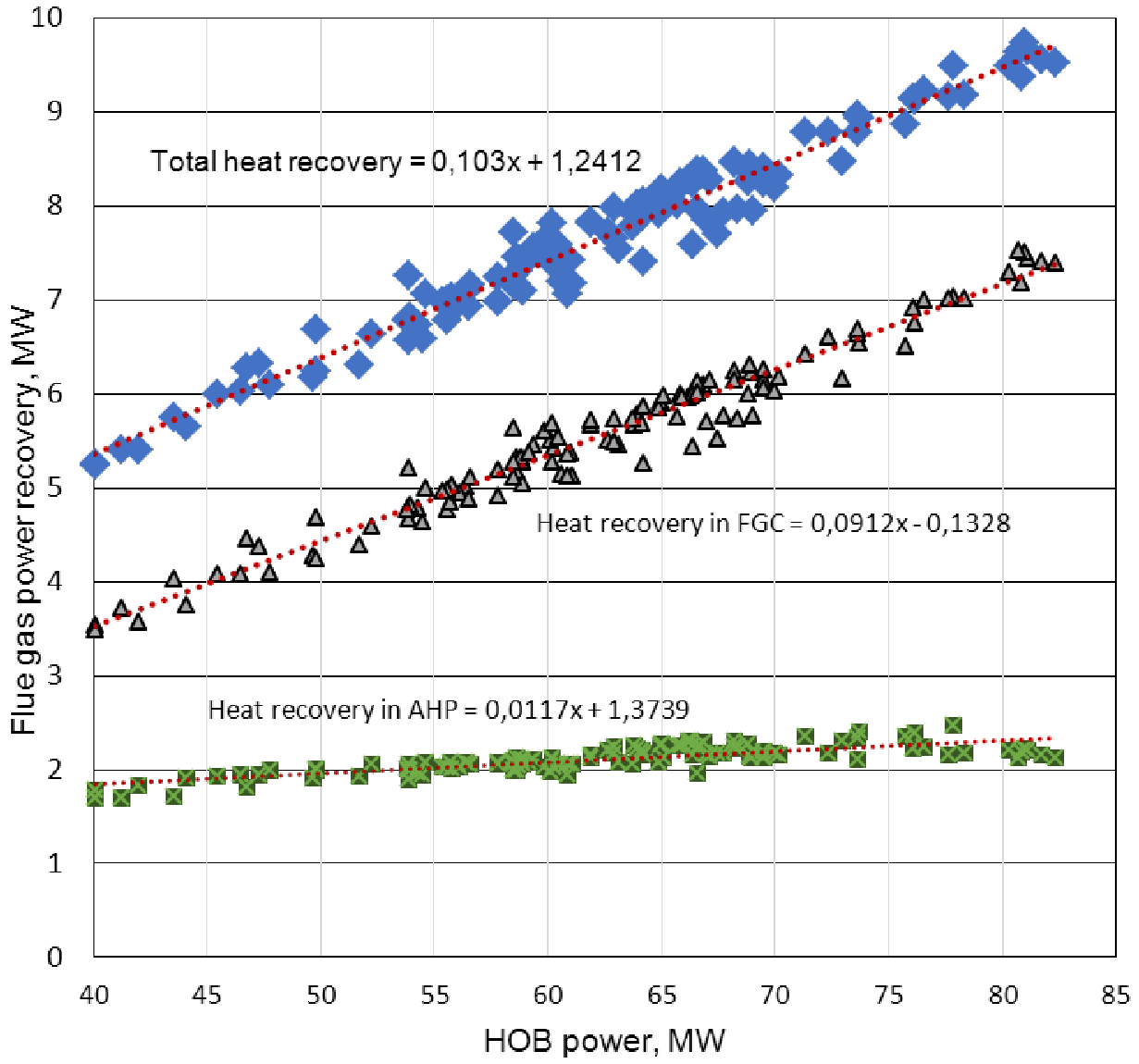

Fig. 5. Flue gas power recovery: in $\operatorname{AHP}\left(Q_{r e c}\right)$, in $\operatorname{FGC}\left(Q_{f g c}\right) \Delta$ and total heat recovery from flue gas $\left(Q_{\text {rec }}+Q_{f g c}\right) \diamond$

It is possible to see that waste energy total recovery follows to HOB growth with certain deviation. For HOB power $40 \mathrm{MW}$, the total recovery is $5.2 \mathrm{MW}$, then it should be for HOB power 80-10.4 MW, but in real operation the recovery value is only $9.5 \mathrm{MW}$. This $10 \%$ deficit of recovery 
can be explained bymuch slower growth of $Q_{\text {rec }}$ - recovery by AHP application. When HOB power becomes doubled from 40 to $80 \mathrm{MW}$, the recovery by AHP, or the value of $Q_{\text {rec }}$, increases only by 35$40 \%$.

The empirical equations presented in the charts in Fig.3 to Fig. 5 represent the influence of HOB power and return temperature $T 2$ on the recovery efficiency by the COP value and the power output from AHP operation.

Additional efforts are requested to gain a general recovery description as a function of various operational parameters of the heating system.

\section{Conclusions}

1. Experimental and theoretical papers considered above prove that profound cooling of flue gas by AHP had wide range of applications: for coal, biomass and natural gas-fired boilers. The thermal efficiency of gas-fired HOB could be improved up to $16 \%$, if the flue gas temperature can be reduced to $25-35^{\circ} \mathrm{C}$ [2].

2. Given paper discloses that AHP had limitation by the rated power as $2.1 \mathrm{MW}$. Therefore, Qrec is not able to overcome the observed level. Obviously, the capacity of AHP does not match the FGC rated power, when the HOB output reaches the rated level. Joint operation of AHP and FGC requests more flexibility in wider range of power.

3. There are lot of mature components (flue gas condensers, absorption chillers, heat exchangers, etc.) for efficient energy recovery from flue gas. But there are still not enough recommendations for sizing of AHP rated power for different operation conditions.

4. The data presented in the paper about the AHP efficiency for the natural gas-fired boiler delivering heat to DHN reveal the flue gas power recovery of $9.5 \mathrm{MW}$ for the total power output of $80 \mathrm{MW}$.

5. Application of AHP with FGC presents the way toenhance the total efficiency for the heating system of the fourth and fifth generation, where the return flow temperature will be lower than nowadays.

\section{Acknowledgements}

This research is funded by the Ministry of Economics of the Republic of Latvia, project "Innovative smart grid technologies and their optimization (INGRIDO)", project No. VPP-EMINFRA-2018/1-0006.

\section{References}

[1] Hou J., Che D., Liu Y., Jiang Q. A new system of Absorption Heat Pump Vs. Boiler for recovering Heat and water Vapor in Flue gas. Energy Procedia, vol. 152, 2018, pp. 1266-1271.

[2] Che D, Liu Y, Gao C. Evaluation of retrofitting a conventional natural gas-fired boiler into a condensing boiler. Energy Convers Manage, vol. 45, 2004, pp. 3251-3263.

[3] Westerlund L., Hermanson R., Fagerström J. Flue gas purification and heat recovery: A biomass fired boiler supplied with an open absorption system. Applied Energy, vol. 96, 2012, pp. 444-450.

[4] Yang B., Jiang Y., Fu L., Zhang S. Conjugate heat and mass transfer study of a new open-cycle absorption heat pump applied to total heat recovery of flue gas. Applied Thermal Engineering, vol. 138, 2018, pp. 888-899.

[5] Yang B., Yuan W., Fu L., Zhang S., Wei M., Guo D. Techno-economic study of full-open absorption heat pump applied to flue gas total heat recovery Energy, vol. 190, 2020, 116429

[6] Sauhats A., Kozadajevs J., Dolgicers A., Zalitis I., Boreiko D. The Impact of the District Heating System Thermal Inertia on the CHPP Operation Mode. In: 60th International Scientific Conference on Power and Electrical Engineering of Riga Technical University (IEEE 2019, RTUCON), Riga, Latvia.

[7] Sauhats A., Kozadajevs J., Dolgicers A., Zālītis I., Boreiko D. Thermal Energy Storage for CHP in Power Market Conditions. In: 16th European Energy Market Conference (EEM 2019), Slovenia, Ljubljana, 18-20 September 2019. 